\title{
Effects of TV Crime Shows on Behavioural Development of Children
}

\author{
Mudassar Abdullah ${ }^{1, *}$, and Nik Adzrieman B. Abd Rahman ${ }^{2}$ \\ ${ }^{1}$ Ph.D. Scholar, School of Multimedia Technology and Communication, University Utara Malaysia \\ 06010 Sintok Kedah, Malaysia \\ ${ }^{2}$ Senior Lecturer, School of Multimedia Technology and Communication, University Utara Malaysia \\ 06010 Sintok Kedah, Malaysia
}

\begin{abstract}
Television crime dramas and shows are very popular all over the world. This popularity is not bound to a certain age group, rather all the TV viewers like these shows very much. Like other countries, dozens of TV channels are telecasting these crime shows in Pakistan. Furthermore, few of the channels telecast crime shows at prime time which attests the popularity of such genre. Some of the media contents behave in morally disputed ways. The crime depictions as re-enactments of TV crime shows are questionable in the field of research signifying diverse cultural contexts. A large number of people are habitual to watch these shows, which may probably come out with negative behavioural outcomes. Especially the children who are at their behavioural developmental phase; are more susceptible to adopt negative behavioural leanings. In this research effort, introduction and detail of TV crime shows in Pakistan are provided, the literature concerning "media as risk factor" in children development is discussed, and relevant theories inferences are deliberated.it was found that media has powerful role in behaviour formulating of children and violence media portrayal (TV crime shows) may appear with grave concerns. Previous scientific literature was reviewed to find and discuss the problem in hand. In the research effort, the literature review provides research propositions to explore further dimensions to TV crime shows' effects and possible negative or positive behavioural outcomes in children behaviour.
\end{abstract}

\section{INTRODUCTION}

Some programs of media entertainment industry are generally perceived to be "good programs", but some other programs are considered as immoral at least some of the time. However, these immoral programs are often liked and watched by a large number of

* Corresponding Author: mudassar80d@yahoo.com 
viewers. Crime shows are comparatively a new genre in Pakistani television industry. This type of programs was introduced five or six years before in Pakistan, since then very popular among all segments of viewers. In a simple definition, crime show/drama is "A story or drama about the investigation of a crime by the police" [1]. In Pakistan, the crime shows are produced with few modifications in which a real crime event is presented by reenactments. The primary focus of these shows is to describe the fare of criminal acts taken from real life events. However, there may be some other effects of these crime shows having negative behavioural tendencies in viewers, especially children.

Last five decades of media research attest to the potential power of media to influence virtually all concerns that societies have about young people, ranges from aggressive behaviour, drugs, obesity, school performance, depression and suicide [1]. It is also argued that media cannot be accused being the main player on such behavioural problems, but it can make a considerable contribution. At one hand we have good behaviour impacts of different TV programs on children (e.g. Sesame Street in increase school readiness) [2], on the other hand, some other programs increase the risk of negative behaviour development in children [4-6]. In this complex behavioural implications, television programs can be powerfully beneficial in the lives of children; but, much more research is needed in this area to recognize better usage of modern media and act accordingly [6].

\section{Purpose}

The purpose of this paper is to detect the need for research in media (television) effects. From general to specific, only one type of TV content (television crime shows) is in focus. Research on the effects of television crime shows on children in their behaviour development may provide new comprehensions. Moreover, this paper is intended to the social context of Pakistan, where the TV crime shows are very popular for last few years.

\section{Methodology}

The existing literature is used to explore and fulfil the purpose of this paper. Previous literature provides the findings of the topic chosen as well as the further dimensions to conduct more research. The major intention of the literature review is to provide, evaluate, analyse and then synthesize the knowledge shared by other researchers focusing the problem under study. For this paper, the literature review on the behaviour formulation of children by media and the theoretical inferences is made to provide dimensions for future research.

\section{TV Crime Shows in Pakistan}

In television format, the technical term to identify the crime shows is "procedural". Procedural shows represent a type of shows in which a problem (mostly crime related) is introduced, its complete procedure is elaborated, then solved. All this process follows a process beginning with the climax of crime. Later, the different stages of the problem or issue are particularised by showing past events. Mostly, the criminal is caught by police as these are based on real solved police cases. All the issue is portrayed like drama show with the help of re-enactments. Few of the examples of these crime shows at international lever are CSI, Law \& Order and NCIS. Few of such genre programs in Pakistani news channels are "Shabbir tou Dekhay Ga" (Express News), "Meri Kahani Meri Zabani" (Samaa), "Wardaat" (Sama), and "Aisa Karega Tou Marega" (Express News). The above 
procedural dramas (crime shows) of different private TV channels are very famous in the country due to its dramatic nature, lack of long storylines, and true events depictions.

\section{Behaviour Development of Children and Media as a Risk Factor}

Child psychologists observed that most of the children experience a single psychological or physical risk factor suffered little if any continuing harm, but multiple risk factors can lead to psychological disorder [7]. From these multiple risk factors, media influence can be a significant factor to investigate. Recent research evidence raises concern about media effects of on children aggression, substance usage, sexual behaviour, eating disorders and academic difficulties [8]. Excessive watching of television during childhood appears significantly in a criminal conviction, personality disorder with aggressive behaviour tenets [9]. Primarily, the psychological processes of behaviour development of children rely on learning with observation, and with frequent exposure to specific media content, the cognitive, emotional and perceptual responses can be predicted [10].

Few longitudinal studies, many static observational studies, and numerous experimental studies indicate that TV exposure (violent content) is related to antisocial behaviour in children [11-12]. Huesmann, Moise-Titus, Podolski, and Eron [13] found that children's TV viewing containing violence is significantly correlated with later aggression. In sum, children spend more time watching TV and other media than doing any other routine activity [14], [15], and some of the content may have effects on key behaviours including antisocial behaviours and aggression. Furthermore, it is also witnessed that children might use media to facilitate the key developmental process in their social context. For further research, it is significant to examine media use through a developmental lens in studying behaviour development of children. Research on children viewership of TV crime shows may help to understand why they watch and like these shows and what influences they adopt from.

\section{Theoretical Inferences}

A significant body of social theory has developed in explaining the processes through media exposure have effects on viewers. According to Coyne and colleagues [14] there is two theoretical bases in terms of the role of media in childhood and adolescence. One rationale includes the theories of media effects, such as Social Learning Theory [16], Cultivation Theory [17], Information Processing Theory [18], and the General Aggression Model [19]. These theories are based on the notion that media have some effects on children and adolescents, whether good or bad, either on attitudes or behaviour. On the other hand, another way of investigating media role provided by Used and Gratifications Theory [20]. This theory rational is that adolescents/children gravitated toward media as they have specific needs and media help them to fulfil these needs [21]. A detailed investigation of previous literature reveals that children use media to satisfy their specific psychological needs, however, they are influenced by media in different aspects.

Research on controversial television contents combining social learning theory, reveals that violence content increases the likelihood of antisocial, aggressive and violent behaviour in long-term as well immediate contexts [22]. Furthermore, social leaning theory explains that repeated observation of real life antisocial/aggressive models portrayed in media like TV, children develop a behaviour that aggression is proper, and then they obtain scripts of how to behave aggressively [23]. In this context, social learning theory has become one of the important theories to investigate behaviour development of children 
denoting the research on TV effects. On the other hand, cultivation theory postulate that television is the most powerful storyteller in a culture, which repeats the ideologies and myths, facts and pattern of relationships that elucidate the social order [24]. Repeated dose of $\mathrm{TV}$, over time, acts like the pull of gravity toward an imagined centre which results in a shared set of concepts and expectations about reality among diverse viewers [25]. As the proposed area of interest is TV crime shows' effects of children, so cultivation analysis has its worth to study behaviour development through a specific TV show.

The social information processing intent attribute is being considered as one optional mediator in media effects research relating violence. The previous professional literature argues that social instability and hostile attribution are quite associated and has well demonstrated with adults as well as with children [26-27]. Crick [28] further investigated and found that hostile acknowledgement is theorized to contribute to the development of aggressive behaviours in children. In this reference, the social information processing theory has its own significant to investigate behaviour development of children with reference to TV crime shows. The General Aggression Model (GAM) [19] is another theoretical perspective to explain the development of aggressive cognitions, attitudes, and behaviours. This model states that "exposure to media violence may contribute to enhancing or mitigating the aggressive constructs"[29]. Anderson and his colleagues GAM describes that exposure to violent media content can affect aggressive thoughts and feelings then arousal [30], which may lead to some negative outcomes. Television viewing, especially watching a specific content may be a meaningful way to investigate behaviour development of children [31]using uses and gratification [32] approach. Previous literature attests that viewers seek out various type of media content to fulfil their certain needs [33], so the TV viewing by children to a specific content (TV Crime Shows) may be investigated through uses and gratifications theory.

\section{Propositions}

The main focus of this paper is to analyse the possible negative and positive effects of TV crime shows in Pakistan. Due to the content sensitivity of TV crime shows and fewer research in this area, it is scientific need to investigate further. The following propositions may be important to consider further research in behaviour development of children in the Pakistani context.

- Television Crime Shows develop negative behavioural leanings in children

- Television crime shows provide a procedural script to children who intend to commit a crime

- There are few positive inferences of TV crime shows on the behaviour of children

- Children watch TV crime shows to satisfy their previous behaviour formulations

\section{Conclusion}

Research on behaviour development of children with reference to antisocial behavioural tendencies has been nourishing for last few decades. What children learn, how children learn, these are two burning questions for child psychologists and social scientists. Different contents of media have always been in research focus to measure its effects on viewers. These contents are also linked with behaviour development of viewers. TV crime shows are popular in Pakistan among different segments of viewers. The purpose of these shows is to convey hatred with crime, and depict the distressing outcomes of crime, but the way of presentation of this message need to be investigated. As these programs show a criminal happening via re-enactments, the background of this event, and the relevant 
proceedings later on, which may cause harmful behavioural implications in children. Different dimensions of behavioural implications on children by the crime shows need to be investigated in media effects and usage research.

\section{References}

1. V. Strasburger, B. Wilson, and A. Jordan, Children, adolescents, and the media. $2^{\text {nd }}$ edition. Thousand Oaks (CA): Sage, (2009)

2. S. Fisch, R. T. Truglio, and C. F. Cole, The impact of Sesame Street on preschool children: A review and synthesis of 30 years' research, Media Psychol., 1, 2 (1999)

3. B. A. Dennison, T. A. Erb, and P. L. Jenkins, Television viewing and television in bedroom associated with overweight risk among low-income preschool children, Pediatrics, 109, 6 (2002)

4. C. Jackson, J. D. Brown, and K. L. L'Engle, R-rated movies, bedroom televisions, and initiation of smoking by white and black adolescents, Arch. Pediatr. Adolesc. Med., 161, 3 (2007)

5. M. M. Garrison, K. Liekweg, and D. a Christakis, Media use and child sleep: the impact of content, timing, and environment, Pediatrics, 128, 1 (2011)

6. V. C. Strasburger, A. B. Jordan, and E. Donnerstein, Children, Adolescents, and the Media: Health Effects, Pediatr. Clin. North Am., 59, 3 (2012)

7. M. Rutter, Stress, coping and development: Some issues and some questions., J. Child Psychol. Psychiatry., 22, 4 (1981)

8. V. et al. Strasburger, Health effects of media on children and adolescents, Pediatrics, (2010)

9. L. a Robertson, H. M. Mcanally, R. J. Hancox, A. L. a Robertson, and M. Helena, Childhood and Adolescent Television Viewing and Antisocial Behavior in Early Adulthood, Pediatrics, 131, 3 (2013)

10. J. Maier and D. Gentile, Learning aggression through the media: Comparing psychological and communication approaches, Psychol. Entertain. Media, (2012)

11. L. Huesmann, The effects of childhood aggression and exposure to media violence on adult behaviors, attitudes, and mood: Evidence from a 15-year cross-national longitudinal study., Aggress. Behav., 25, (1999)

12. W. L. J. Pers. Soc. Psychol., 53, 5 (1987)

13. L. R. Huesmann, J. Moise-Titus, C.-L. Podolski, and L. D. Eron, Longitudinal relations between children's exposure to $T V$ violence and their aggressive and violent behavior in young adulthood: 1977-1992., Dev. Psychol., 39, 2 (2003)

14. S. M. Coyne, L. M. Padilla-Walker, and E. Howard, Emerging in a Digital World: A Decade Review of Media Use, Effects, and Gratifications in Emerging Adulthood, Emerg. Adulthood, 1, 2 (2013)

15. Alloy and M. \& Marketing, "Alloy Media \& Marketing," http://www.marketingcharts.com, (2016)

16. A. Bandura, D. Ross, and S. a. Ross, J. Abnorm. Soc. Psychol., 66, 1(1963)

17. G. Gerbner and L. Gross. J. Commun., 26 (1976)

18. L. R. [Ed] Huesmann and L. D. [Ed] Eron, Television and the aggressive child: $A$ cross-national comparison, Telev. Aggress. child A cross-national Comp, (1986)

19. C. A. Anderson and B. J. Bushman, Human aggression, Annu. Rev. Psychol., 53, (2002)

20. E. Katz, J. G. Blumler, and M. Gurevitch, Utilization of mass communication by the individual, Crit. readings media audiences, 5578 LNCS, 19-31, (1974) 
21. A. M. Rubin, The uses-and-gratifications perspective of media effects., Media Eff. Adv. theory reserach,165-184, (2002)

22. C. a. Anderson, L. Berkowitz, E. Donnerstein, L. R. Huesmann, J. D. Johnson, D. Linz, N. M. Malamuth, and E. Wartella, The influence of media violence on youth, Psychol. Sci. Public Interes., 4, 3 (2003)

23. B. J. Bushman and L. R. Huesmann, Short-term and long-term effects of violent media on aggression in children and adults., Arch. Pediatr. Adolesc. Med., 160, 4 (2006)

24. J. D. Brown. J. Sex Res., 39, 1 (2002)

25. G. Gerbner, L. Gross, M. Morgan, and N. Signorelli, Growing up with television: the cultivation perspective, (1994)

26. K. A. Dodge and C. L. Frame, Social cognitive biases and deficits in aggressive boys., Child Dev., 53, 3 (1982)

27. [27] N. R. Crick and K. a. Dodge, A review and reformulation of social information-processing mechanisms in children's social adjustment., Psychol. Bull., 115, 1 (1994)

28. N. R. Crick, Relational aggression: The role of intent attributions, feelings of distress, and provocation type, Dev. Psychopathol., 7, 2 (1995)

29. D. A. Gentile, S. Coyne, and D. A. Walsh, Media violence, physical aggression, and relational aggression in school age children: A short-term longitudinal study, Aggress. Behav. 37, 2 (2011)

30. C. a Anderson and K. E. Dill, Anderson, C. A., \& Dill, K. E. J. Pers. Soc. Psychol., 78, 4 (2000)

31. A. M. Rubin. J. Broadcast., 27, 1 (1983)

32. W. J. Severin and J. W. Tankard, Communication Theories: Origins, Methods, and Uses in the Mass Media. (2010)

33. S. M. Coyne, L. M. Padilla-Walker, and E. Howard, Emerging in a Digital World: A Decade Review of Media Use, Effects, and Gratifications in Emerging Adulthood, Emerg. Adulthood, 1, 2 (2013). 